\title{
Using the project method to improve environmental education for law students
}

\author{
Sergey Yekimov 1,*, Yevhenii Karmanny ${ }^{2}$, Andrii Zenin ${ }^{2}$, Iliana Zinovatna ${ }^{2}$ and \\ Serhii Sliusarenko ${ }^{3}$ \\ ${ }^{1}$ Publishing House "Education and Science" s.r.o., Olstynska 607/1, Praha 8 , 18100 ,Czech \\ Republic \\ ${ }^{2}$ Yaroslav Mudryi National Law University, st. Pushkinska, 77, 61024 Kharkiv, Ukraine \\ ${ }^{3}$ National University of Life and Environmental Sciences of Ukraine, Heroiv Oborony St, 15, Kyiv, \\ Ukraine
}

\begin{abstract}
Training a modern professional who can use a creative approach within the framework of their professional activities, as well as to easily adapt to many modern technological changes, requires the use of modern innovative pedagogical technologies in the training process. When performing this study, we used the project method to increase environmental awareness and environmental thinking among students of the specialty law. Environmental education is learning through the environment, for the environment, and about the environment. The authors believe that it should be universal, and its components should be present in preschool, school, vocational, higher, and postgraduate professional education. We believe that the greatest effect can be achieved by continuing environmental education, provided that it becomes an indispensable attribute of personal development. The results of the implemented project showed that the students of law have increased their
\end{abstract}

\section{Introduction}

The training of a modern highly educated professional, capable of a creative approach in their professional activities, and easy adaptation to modern technological changes requires the use of the latest innovative technological approaches in the educational process.

Authors [1] educational technologies are understood as purposeful educational activities that are aimed at achieving a certain educational result.

According to [2] educational technology must include the purpose, content, methods of organization of teaching process, tools, pedagogical impact, and control of the result of its use.

According to[3], there are two main technologies for organizing the educational process (Figure 1):

\footnotetext{
*Corresponding author (Автор-корреспондент): 3701313@mail.ru
} 


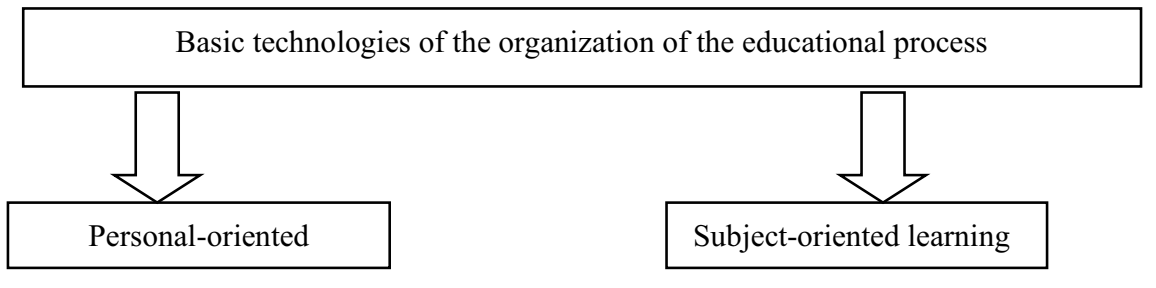

Figure1. Basic technologies of the organization of the educational process.

According to [4] in the modern educational process, there is a shift from traditional reproductive approaches to learning to innovative educational technologies based on pedagogical approaches of the developing type. For educational technologies of the developing type, there is a wide application of activating the creative potential of teachers and students. The acceleration of scientific and technological progress leads to the need for self-education and continuing education. The formation of students ' communicative competencies contributes to the formation of their personal, emotional and moral-spiritual consciousness. The development of students ' reflexive thinking contributes to their personal, professional and social self-determination. This is of great importance in the context of the development of modern society .

Subject-oriented training, in our opinion, is most suitable for obtaining new knowledge that allows them to be used in their professional activities. In this regard, the use of developing communicative technological approaches based on design, research and educational activities in the educational process is of great importance.

Economically highly developed countries form their economic policies based on the greening of production and scientific research. In these conditions, universal environmental education can serve as an important tool for ensuring the harmonious development of the state and the foundation of its environmental security.

In the opinion of [5,6] environmental safety should be at the heart of the worldview of modern man. Unfortunately, the level of environmental awareness of political leaders and ordinary citizens is negatively affected by the view that environmental requirements can hinder the development of the economy.

According to $[7,8]$, environmental awareness should be a component of environmental education .

In the opinion of [9] the following factors influence the process of formation of ecological consciousness in a person (Figure 2):

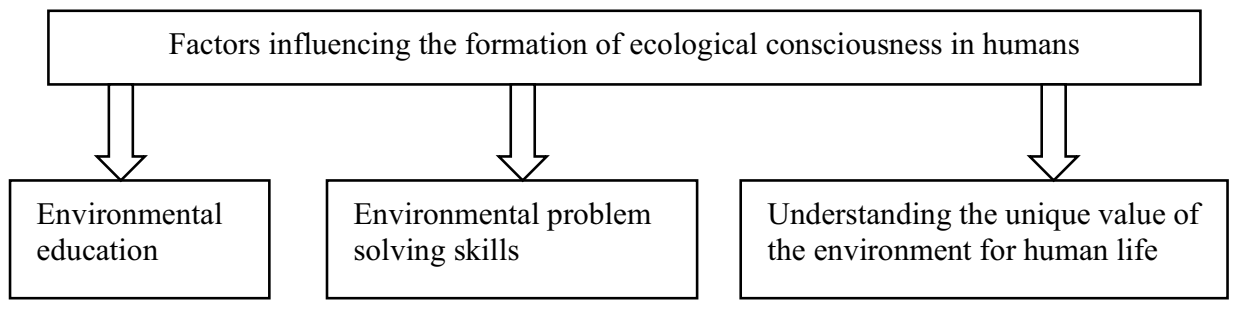

Fig. 2. Factors influencing the formation of ecological consciousness in humans

Environmental education, according to [10], should not be limited only to the study of environmental educational disciplines, it should also provide for the formation of an environmental culture and environmental thinking among students.

According to [11, 12], environmental thinking should include:

1. Understanding the causes of environmental problems.

2. The desire to fight for the protection of the environment.

3 . Understanding the depth of the environmental crisis in the modern world.

4. Reliance on scientific knowledge in the field of ecology. 
The system of environmental education will be effective if the student acquires the skills to correctly interpret the impact of human activity on the environment. Modern environmental education, in our opinion, should provide not only for the study of the biosphere in all its variety of forms, but also for the legal, social, economic and political functions of people in it.

In our opinion, the formation of students ' ecological thinking should include an understanding of the cause-and-effect relationships between human influence on the environment and the natural processes and phenomena observed in the modern world.

\section{Methods}

During the execution of this study, the authors used an analytical method by which the problems considered in it were considered in their unity and development.

Taking into account the goals and objectives of this study, a functional and structural method of performing scientific research was used.

In the end, this made it possible to consider some issues related to the use of projectbased learning for environmental education.

\section{Results}

Within the framework of this research work, we have attempted to develop ecological thinking and ecological consciousness among students of the Law Faculty of the Dnipro National University.

The city of Dnipro is a major industrial center of Ukraine, on its territory there are large enterprises of the chemical and metallurgical industry, which have a negative impact on the environmental situation not only of the city of Dnipro, but of the entire Dnipropetrovsk region.

As an educational technology, we used the project method.

The project method allows trainees to participate in solving some practical problem . In this case, the students were asked which regulatory documents of the environmental legislation of Ukraine most violate the enterprises of the city of Dnipro that pollute the environment, and what changes should be made to the environmental legislation . to reduce the level of this pollution. The result of this project should have been a presentation made in English.

At the beginning of the study, we conducted a survey of students, which found out :

1) What environmental problems of the city of Dnipro do they care about?

2) Who should be involved in solving environmental problems?

3) Whether law students are required to further study the basics of ecology.

The results of the survey conducted on the same issues that were at the beginning of the study showed the following results : $45 \%$ of respondents noted that the main environmental problem of the city of Dnipro is harmful emissions of motor transport, $48 \%$ of respondents noted that the main environmental problem of the city of Dnipro is harmful emissions of industrial enterprises. $67 \%$ of respondents noted that only authorized state regulatory bodies should deal with environmental problems of the city of Dnipro, $30 \%$ of respondents noted that all residents of the city of Dnipro should deal with environmental problems of the city of Dnipro . 34\% of respondents noted that it is necessary for law students to study the basics of ecology, and $57 \%$ of respondents noted that it is not necessary for law students to study the basics of ecology.

When implementing the project, students used open information located on the websites of state environmental organizations, regulatory documents in the field of environmental law, as well as other information located on the Internet.

As a result of the project, the students established : 
1) Many industrial enterprises prefer to pay a fine for environmental pollution, rather than use wastewater treatment plants to clean up harmful emissions.

2) One of the largest metallurgical enterprises only partially uses its treatment facilities when working on the night shift.

As a result of the project implementation, the students prepared a presentation, during its preparation, the students were advised by teachers of the Department of Environmental and Land Law, as well as teachers of the Department of English.

Representatives of the city authorities responsible for environmental protection activities were invited to present the presentation.

At the end of the project, we re-conducted the survey of students. The results of the repeated survey were as follows: $45 \%$ of respondents noted that only authorized state regulatory bodies should deal with environmental problems of the city of Dnipro , $43 \%$ of respondents noted that all residents of the city of Dnipro should deal with environmental problems of the city of Dnipro . 65\% of respondents noted that it is necessary for law students to study the basics of ecology, while $31 \%$ of respondents noted that it is not necessary for law students to study the basics of ecology.

The project method allows trainees to participate in solving some practical problem. When implementing the proposed project, the following results were obtained:

1) We were able to encourage students to add to their knowledge of environmental issues.

2) The trainees have expanded their vocabulary in the field of environmental law and including English-language terms.

3) Students got acquainted with the environmental legislation of the economic developed countries, as well as with the environmental measures that are applied in these countries.

4) The trainees have acquired teamwork skills, which are very necessary for them to continue their professional activity as a lawyer.

5) Students gained the skills of research activity and independent acquisition of new knowledge

6) The students understood the importance of environmental problems for the city of Dnipro, and that their effective solution requires joint actions not only of environmental organizations, but also of all residents of the city.

\section{Conclusions}

Environmental education is learning through the environment, for the environment, and about the environment.

In our opinion, it should be universal and its elements should be present in preschool, school, vocational, higher, and postgraduate education.

We believe that continuous environmental education can achieve the greatest effect if it becomes an indispensable attribute of personal development.

Environmental education is the process of training, education, self-education and development of a person who is focused on the formation of norms of behavior and the acquisition of special knowledge and skills necessary for competent environmental management and environmental protection.

Modern environmental education, in our opinion, should be practice-oriented, since all people face environmental problems in their lives. 


\section{References}

1. M. Kolodziejski \& M. Przybysz-Zaremba, Project Method in Educational Practice. University Review. 11. (2017).

2. M. Nalej \& J. Rogowski, (2015). The Project Method in Education of Geoinformation Specialists. "GIS in Higher Education in Poland. Curriculums, Issues, Discussion" 75-89 (Jażdżewska, Wydawnictwo Uniwersytetu Łódzkiego, Łódź, 2015)..

3. C. Sirrine, Journeying through the landscape : the project method of education (2021).

4. B. Tulayev, The project method in higher education. 27-29 (2018).

5. Ch. Sharma, Environmental awareness (2020).

6. P. Sahoo, Pollutions and Environmental Awareness (2019).

7. Z. Bacsi, Visegrad J. on Bioeconomy and Sust. Development, 9, 47-54 (2020).

8. R. Bhargava, V. Rajaram \& Olson, Keith \& L. Tiede, Education for Environmental Awareness (2019).

9. R. Bhargava, V. Rajaram, K. Olson \& L. Tiede, Education for Environmental Awareness (2019).

10. A. Kavitha, R. Sasipriya \& S. Priya, Environmental awareness of high school students. (2020).

11. A. Eitel, Environmental Aware Vulnerability Scoring, 478-485 (2020).

12. N. Davies, IEEE Pervasive Computing, 9, 2-3 (2010). 